\title{
La proyección urbana de un creador: Víctor Jara y la canción "Las casitas del barrio alto"
}

\author{
Laura Y. Rodríguez ${ }^{1}$ \\ Universidad Austral de Chile, Valdivia, Chile. \\ Email: lrodrigueztitulo@gmail.com
}

\begin{abstract}
Resumen: Los fenómenos urbanos son objeto de complejos modelos cuantitativos que persiguen explicar la emergencia de futuras tendencias. De similar manera, la intuición opera en algunos visionarios, cuya propiedad de percibir lo que esta por venir, los acerca a la realidad de un modo distinto. Este es el caso de Víctor Jara, cuya canción "Las Casitas del Barrio Alto" es objeto de estudio a través de un análisis crítico del discurso. En el trabajo se aprecia que Víctor Jara tiene la capacidad de anticipar el futuro con esta canción, enunciando las características de lo que seria el porvenir urbano de Chile post dictatorial.
\end{abstract}

Palabras clave: Dinámica urbana, Víctor Jara, metrópolis, Santiago

\section{The urban projection of a creative person: Victor Jara and the song "Las Casitas del Barrio Alto"}

\begin{abstract}
The urban phenomena are object of complex quantitative models, which intend to explain the emergence of future tendencies. In a similar way, the intuition works with some visionaries, whose quality to perceive what is to come, approaches them to reality in a different manner. This is the case of Victor Jara, whose song The Small houses of the Rich neighbourhood" is the object of this study through a critical analysis of the discourse. In this research, one can see that Victor Jara, in this song, has the capacity to anticipate the future, expressing the characteristics of post dictatorial urban Chile.
\end{abstract}

Keywords: Urban dinamic, Víctor Jara, metropolis, Santiago

\section{A projeção de uma persona criativa: Victor Jara e sua canção "Las Casitas del Barrio Alto"}

Resumo: Os fenômenos urbanos estão sujeitos a complexos modelos quantitativos que procuram explicar o surgimento de tendências futuras. De maneira semelhante, a intuição opera em alguns visionários, cuja propriedade de perceber o que está por vir, o mais próximo da realidade de uma maneira diferente. Este é o caso de Victor Jara, cuja canção "Las Casitas del Barrio Alto" é estudada através de uma análise crítica do discurso. O artigo mostra que Victor Jara tem a capacidade de antecipar o futuro com essa música, definindo as características do que se tornaria o futuro urbano pós Chile ditatorial. 
Palavras-chave: dinâmica urbana, Victor Jara, metrópole, Santiago

\section{Introducción}

Víctor Jara, no es un individuo habitual para su época. Como creador y artista, fue al mismo tiempo un visionario, cuya imaginación lo proyectó en el tiempo, adelantándose a su época. La misma cualidad lo facultó a la hora de examinar el espacio, reconociendo tenues destellos de las tendencias urbanas que posteriormente ocuparían un lugar central en la construcción de la ciudad del siglo XXI

El artista es en si mismo una transición entre el modernismo y el posmodernismo, su pensamiento, materializado en sus obras, demuestra que entiende con una gran precisión la conformación de la sociedad que le tocó vivir. La hipótesis planteada en esta investigación establece que el artista, a partir de la intuición matematizadora con la que aborda su quehacer, es capaz de distinguir las tendencias urbanas más relevantes que conformarán el proyecto de ciudad venidero.

En aquel entonces, las características enunciadas en la canción "las Casitas del Barrio Alto” y sobre todo en la introducción que él hace antes de interpretar esta melodía, corresponden a tímidos gestos, esbozos imperceptibles para el habitante contemporáneo. No obstante para Jara, acostumbrado a examinar minuciosamente su realidad en la búsqueda constante de la inspiración, estos rasgos eran ya evidencia de un acontecer desplazado de la ciudad modernista y su proyecto centrado en la intervención del estado.

\section{Metodología}

El trabajo propuesto se lleva a cabo sobre la base de un análisis crítico del discurso introductorio a la canción "Las Casitas del Barrio Alto" de Víctor Jara, junto con el análisis de la canción propiamente tal. La necesidad de incorporar la introducción que Jara hace a la canción, se relaciona con aspectos abordados por él, en los cuales clarifica el sentido de las “Casitas del Barrio Alto”. Conceptos que si bien se intuyen en la canción, son definidos con mayor precisión en la introducción. Todas estas forman parte de una nomenclatura que permite un mayor entendimiento de la proyección de su pensamiento urbano, el cual yo denomino intuición matematizadora ${ }^{2}$.

En la primera parte de esta investigación se elabora una descripción del espacio urbano, abordando los principales ejes sobre los cuales se estructuró la ciudad de Santiago que Víctor Jara habitó. Estos ejes son el transporte, la expansión urbana, la morfología del barrio alto, etc. La revi- 
sión de la literatura que aborda las transformaciones espaciales sufridas por la ciudad chilena, tiene no solo una dimensión espacial, sino también temporal. Esto último permite entender la dinámica de la ciudad que vivió Víctor Jara, pero también aborda la dinámica de la urbe en los últimos 30 años, en donde se evidencia la propagación de los fenómenos enunciados por Jara en su canción.

Por lo anterior es que es fundamental revisar las transformaciones surgidas, especialmente a partir de los años 1980, como un punto de inflexión en la variación urbana. Al mismo tiempo es preciso analizar las tendencias emergentes a partir de los gobiernos democráticos, los cuales, no han introducido sustantivas reformas al modelo económico-político de las ciudades, lo cual en última instancia significa que la trayectoria de la ciudad chilena ha seguido sin grandes variaciones el camino trazado por la dictadura militar.

La introducción de la canción, se analiza críticamente estructurando este análisis en dos partes. En la primera, Víctor Jara aborda el espacio urbano característico del barrio alto de santiago y otras metrópolis de Latinoamérica. En la segunda parte del análisis de la canción, este se orienta hacia la ideología y la tensión subyacente de la época, donde se distingue la claridad del artista a la hora de transitar de la modernidad a la postmodernidad. En última instancia, se analiza la letra de la canción, estableciendo las vinculaciones de esta con la introducción.

\section{La metrópoli desde los tiempos de la guerra fría}

En la década de los setenta, la ciudad de Santiago que vivió Víctor Jara era notablemente más compacta que en la actualidad. En 1958 había sido lanzado el Plan intercomunal de Santiago, cuya aprobación sería en definitiva el 10 de noviembre de 1960 por el Decreto Supremo No 2.387. En este plan se podía encontrar básicamente tres puntos importantes; una regulación del uso urbano, delimitando claramente los espacios naturales y rurales en torno a la capital, cuya dimensión quedó en una superficie de 21.600 hectáreas para la zona urbana y de 17.000 hectáreas para la suburbana, lo que permitiría una población de hasta 3.260.000 habitantes. El segundo consistía en una reestructuración de las obras viales orientado al mejoramiento del transporte interno de la capital ${ }^{3}$. Finalmente, en el tercer punto se proponía trasladar las industrias a zonas especiales conocidas como «cordones industriales», localizados principalmente en los ejes del camino a Melipilla por el poniente, Avenida Vicuña Mackenna en el oriente y la Panamericana Norte.

El barrio alto del tiempo de Víctor Jara, estaba circunscrito a los sectores de Las Condes, Providencia, La Reina y parte de Ñuñoa, concentrados en el sector oriente de la capital. Estos sectores se habían desarrollado especialmente durante el transcurso de la primera mitad del siglo XX, cuando la clase alta emigró desde el centro de Santiago. De acuerdo a 
Sabatini y Arenas (2000), "las elites han tendido a concentrarse en una sola zona de la ciudad, la que se extiende desde el Centro hacia la periferia en una dirección geográfica definida — hacia el nororiente en Santiago”.

Estos mismos autores establecen que las bajas tasas de motorización y las escasas inversiones en obras de infraestructura urbana, especialmente de transporte, fueron posiblemente las causas que explicaban que la ciudad de Santiago presentara una forma compacta. El automóvil era un bien restringido solo a un cierto segmento de la sociedad. De esta manera Tomic y Trumper (2006) argumentan que

En los sesenta keynesianos, el estado y los arquitectos e ingenieros urbanos, todos con inclinaciones modernistas, trataron de planificar la transformación de las ciudades... las posibilidades del automóvil no eran una preocupación, así no se consideraron carreteras ni autopistas como elementos centrales del proyecto ciudad. El interés que guiaba estos planificadores era, al menos ostensiblemente, el progreso social.

Tras el golpe de Estado de 1973 y el establecimiento del Régimen Militar, la planificación urbana de la ciudad, consecuente con la idea del gobierno de adoptar el modelo económico neoliberal, fue reformada a partir de políticas de liberalización del suelo. Bajo este sistema, el Estado comenzó rápidamente a abandonar su rol organizador en beneficio del mercado. (De Mattos, 1991) En esta situación se promulga una modificación en 1979 al plan regulador, que liberalizó el mercado inmobiliario al ampliar el radio urbano a más de 62.000 hectáreas, con el fin de hacer descender los valores de la tierra. De acuerdo a Sabatini y Arenas (2000)

La rebaja o eliminación de impuestos a las transacciones de propiedades o a la tenencia de sitios eriazos, la liquidación de las reservas estatales de suelo formadas en el periodo intervencionista, y la eliminación de la norma sobre límites urbanos y definición de un área abierta a la urbanización que, en el caso de Santiago, casi doblaba el área ocupada por la ciudad.

Esta política tuvo dos objetivos principales: controlar los precios del suelo, que fracasó ya que éstos han subido persistentemente desde entonces, con la excepción de los periodos de crisis económica; y la formación de un vigoroso sector inmobiliario privado, objetivo en que la política tuvo pleno éxito.

Sin embargo, la crisis económica del año 1982 haría que los valores se mantuvieran o se encarecieran en las zonas urbanas; esto originaría un mayor crecimiento hacia la periferia, principalmente el sector de La Florida, que en el censo de 1992 se convertiría, con más de 300.000 habitantes, en la comuna más habitada de todo el país, y que dejaría a la ciudad con 40.619 hectáreas de extensión hacia comienzos de los años 1990 
Un urbanismo distinto surgiría a partir de la liberalización de la economía, de la apertura de los mercados, y la masificación de los automóviles fue solo un eslabón en la transformación que esta sociedad padecería. Junto con esto la congestión, el crecimiento de la periferia y la apertura de los centros comerciales en estas periferias, vendrían a convivir con una clase alta re-localizada y una emergente clase media.

La redefinición de la escala de accesibilidad urbana implícita en las obras de infraestructura urbana de los 1960 ha permitido que, desde fines de los años 1970, el emergente capital inmobiliario rompiera el virtual confinamiento de «lo moderno» en el sector nororiente de la ciudad Sabatini y Arenas (2000)

La década de los ochenta trae consigo un evidente deterioro del centro histórico, una creciente terciarización de la economía, la cual ofrece un mercado laboral a partir de la reforma del sistema previsional y de salud, AFP e Isapres respectivamente, (Valdivia, 2001). A este respecto De Mattos (1991) observa que las transformaciones en el sector de servicios, tiene como consecuencia el crecimiento del número de empleos generados por las actividades de transporte y comunicaciones, comercio y servicios financieros. El mismo De Mattos (1991) argumenta que "Este proceso fue acompañado por un sostenido aumento del ingreso per cápita, que se elevó desde 1.360 a 5.151 dólares entre 1985 y 1997, redundando en un sustancial aumento del ingreso de los hogares y en una sostenida reactivación del mercado interno.

En los 90, con el advenimiento de la democracia, la administración del modelo neoliberal fue desempeñada por una coalición contraria a la dictadura, Consolidándose el modelo territorial, expandiéndose la ciudad con sus carreteras. No obstante, el paradigma estatal se había modificado levemente; con un insipiente ordenamiento del territorio, con la inclusión de las áreas verdes dentro de las políticas públicas, el saneamiento de los ecosistemas naturales, daba cuenta de un nuevo orden urbano. Sin embargo, se acrecentó la voracidad de los conglomerados inmobiliarios.

Tras el fin del Régimen Militar y el inicio de los gobiernos de la Concertación, la ciudad de Santiago ya sobrepasaba los cuatro millones de habitantes, que habitaban preferentemente en la zona sur: La Florida era seguida en número de habitantes por Puente Alto y Maipú. Durante gran parte de la década de los años 1990 y como producto del crecimiento económico que vivía el país durante esa época, el desarrollo inmobiliario en estas comunas, se debió en gran medida a la construcción de conjuntos habitacionales para familias de clase media. Estos conjuntos habitacionales también comenzaron a ser construidos en otras comunas de la periferia, como Quilicura hacia el norte y Peñalolén por el oriente. Lo anterior se vio facilitado por la progresiva masificación del automóvil el cual de acuerdo a De Mattos (1991) “En el período 1992-1996 el número de automóviles en la RMS mostró un crecimiento del orden del 42.7\%”. 
Estas comunas con su emergente clase media comenzaron a acceder a los servicios que en otros tiempos eran solo reservados para la clase alta.

Al ritmo de la globalización, surgen los «shopping malls», concebidos como verdaderos sub-centros urbanos, donde determinados barrios o comunas refrendan su identidad constituyéndose en, "la mejor expresión de las nuevas modalidades de espacio público socialmente estratificado de propiedad privada”. De Mattos (1991). De manera similar Cariola y Lacabana (2001) observan en el caso de Caracas Venezuela, que, "El parque, la plaza, la calle, pierden capacidad de atracción frente al centro comercial que se constituye en el ámbito moderno y globalizado del consumo recreacional, lugar de encuentro y de esparcimiento”.

El sector nororiente de Santiago vivió otro desarrollo importante. A medida que pasaba el tiempo, la gente de mayores recursos comenzó a avanzar progresivamente hacia la precordillera, aumentando de manera importante la población en Las Condes y dando origen a nuevas comunas como Vitacura y Lo Barnechea. En su estudio acerca del crecimiento del territorio de Santiago, Ducci (1998) encontró que "Entre 1990 y 1995 la mancha urbana aumentó de 55.000 has a 65.000 has.

Aunque en décadas anteriores, el eje de Avenida Providencia se había consolidado como un sector comercial de gran importancia, es a partir de fines de los años 80 en que el sector oriente de la ciudad se convierte en un polo de atracción para la construcción de innovadores edificios de oficinas de gran altura. A esto se sumó la instalación de los primeros centros comerciales de magnitud, que con el paso de los años se expandieron al resto de la ciudad, convirtiéndose en un centro de atracción y entretención para la población. La lectura frente a este fenómeno que hacen de Sabatini y Arenas (2000) es la siguiente

Esta reducción en la escala geográfica de la segregación está teniendo efectos disímiles: por una parte, hace más evidente las desigualdades sociales que, por lo demás, han aumentado en el período de mercado en Chile como en otros países; y, por otra parte, permite a los vecinos pobres acceder a mejores servicios comerciales (supermercados y shoppings, principalmente), mejores espacios públicos y oportunidades laborales en las cercanías, con un efecto de reducción de sus tiempos de viaje

Por otro lado, aunque la cantidad de gente bajo la línea de la pobreza se redujo, ésta no desapareció de la ciudad y generó una fuerte dicotomía entre la pujante urbe globalizada y los barrios marginales dispersos a lo largo de la capital. Ejemplo de ello es Huechuraba, en cuyo territorio se encuentran campamentos de familias de escasos recursos y condominios exclusivos. 


\section{La intuición como parte de la razón o razonamiento intuitivo}

Sin recurrir a modelos matemáticos que permitan proyectar el crecimiento de la ciudad, más bien solo de la intuición matematizadora como herramienta para distinguir fenómenos aislados, Víctor Jara, esbozó una trayectoria de lo que sería la ciudad por venir.

La intuición no tiene metodología, no por lo menos una que se le conozca, pero su capacidad de aproximarse a la realidad, de imaginar un camino divergente, a veces escabroso, pero sin duda fascinante, no puede ser desconocida. La ciudad que Víctor Jara vivió sin duda era diferente de la actual, no obstante, él pudo percibir con una precisión bastante ajustada fenómenos, que si bien eran aislados, en la actualidad están presentes en prácticamente todas las ciudades del país, aun aquellas que no son metropolitanas.

El paisaje cultural del Chile de los años setenta se conformaba bajo el esquema de una lucha ideológica profunda, en la cual Víctor Jara no estaba al margen. Farish (2003) en su trabajo acerca del urbanismo de Estados Unidos durante el periodo de la Guerra Fría establece que el término geopolítico asociado a este proceso es la “contención”. Íntimamente vinculado a George Kennan y su artículo publicado en la Revista de Asuntos Exteriores del año 1947, establecía que Estados Unidos debía tener una política exterior de contención frente a la amenaza del bloque soviético. La amenaza permanente de un ataque nuclear habría sido un elemento determinante en la dinámica de ciudad dispersa de ese país del Norte y la generalizada actitud anti ciudad, discurso ampliamente reproducido en la mayoría de los países latinoamericanos.

Inserto dentro del clima de la guerra fría, Chile vivió circunstancias profundamente imbricadas en este contexto y de ahí deriva la controversial relación que ciertos sectores del país tuvieron con el gobierno de los Estados Unidos, cuya política de contención tendría un tremendo impacto en el futuro del pueblo chileno.

La creciente tensión surgida a partir de la llegada al poder del gobierno socialista de Salvador Allende en 1970, alertó a algunos partidarios de la Unidad Popular acerca de la creciente tensión, por parte de los sectores conservadores, quienes vieron en este hecho, una amenaza a sus privilegios históricos. De acuerdo a lo que argumenta Vilches (2004)

El compositor se mantuvo agudamente consciente de las vicisitudes políticas de su país, y en su producción musical de 1971 les toma el pelo a los capitalistas, como se aprecia en «Ni Chicha ni Limoná», por su miedo irracional hacia una posible expropiación arbitraria de territorios o una latente revolución armada que terminase con las libertades cívicas. 
En su libro, Víctor un canto inconcluso, Joan Jara (2007) comenta que la anterior canción se burlaba de la gente temerosa de comprometerse con el proyecto de la Unidad Popular, la critica iba sobretodo hacia los demócratas cristianos, quienes debían afrontar una decisión trascendental para el futuro del país.

Sin duda Víctor Jara era un representante de la contracultura, la cual de acuerdo a David Harvey (1989) exploró en algún momento el reino de la autorrealización individualizada a través de una política de nueva izquierda, abrazando nuevos códigos de música, vestuario, lenguaje y una fuerte critica a la vida cotidiana.

La agudeza del compositor a la hora de observar y distinguir circunstancias latentes y su capacidad para crear a partir de estas, queda de manifiesto al revisar su obra. En este plano es que Víctor Jara antes de cantar "las Casitas del Barrio Alto" en el concierto, explicó los términos vertidos en ésta a la audiencia, de manera de clarificar la acida crítica que pretendía abordar.

Lo interesante en esta introducción, junto con la aclaración de los conceptos utilizados en la canción, es que la introducción está claramente dividida en dos partes. La primera conceptualiza desde la perspectiva espacial la intencionalidad de los fenómenos que él percibía. En la segunda parte, Víctor Jara evidencia señales de su condición de transición entre la modernidad concreta y esta nueva post modernidad difusa cargada de símbolos, de representaciones, donde lo real se diluye en un complejo mundo de imágenes.

"Bueno y nosotros seguimos cantando e inventando canciones, creando canciones como esta que les voy a cantar ahora, que trata de un lugar que hay por supuesto en Santiago y que recorriendo Latinoamérica me di cuenta que había en otros lugares también, en otras ciudades; que había en Perú, que había en Colombia en Bogotá, que había en México, en Caracas, lugares así que generalmente están puestos como en unas colinas, my suaves donde el aire es más limpio, donde no tiene contaminación, donde no hay smog que se llama, contaminación atmosférica, donde las áreas verdes son mas hermosas. Entonces claro para estar de acuerdo con el lugar, las casas que se construyen son más grandes, espaciosas a veces son bastante grandes, enormes con ventanales así maravillosos, donde dominan una vista así hacia la ciudad y dominan también a veces más allá de la ciudad.

La política del lugar otorga una identidad para quienes lo habitan, pero al mismo tiempo también para quienes están fuera de él. Especialmente en el proceso de globalización actual, la identidad de los lugares cobra una importancia fundamental acerca de cómo la sociedad es representada. Massey y Jess (1995) explorando el concepto de sentido de lugar, encontraron que "muy a menudo, cuando nosotros pensamos en que queremos 
decir por lugar, nosotros nos figuramos una comunidad establecida; una localidad con un carácter físico, económico y cultural distintivo”

De esta manera, no es casualidad que Víctor Jara, en su canción, designara el objeto central del argumento melódico como "lugar". Tampoco es azar que distinguiera las características espaciales que este supuesto "lugar" tendría. Para el artista, la presencia de estos rasgos presentes solo en el barrio alto, indicaban la obsolescencia de una forma de habitar la ciudad, cuyo proyecto iba abrazado a transformaciones profundas pensadas desde fuera y materializadas al interior del país. Larrain argumenta al respecto

Cuando el proyecto de autonomía se quiebra con las dictaduras en los años 1970, el proyecto de control (ejes centrales del pensamiento moderno) toma un carácter más liberal siguiendo el modelo norteamericano. La democracia retorna en los 1980, pero con un carácter más individualista.

Al nombrar los lugares, Jara esta dando una clara señal de lo que se refiere por casitas del barrio alto. Al iniciar la introducción, él identifica varios lugares que comparten esta identidad de barrio alto y narra que al recorrer "Latinoamérica me di cuenta que había en otros lugares también, en otras ciudades; que había en Perú...” Sigue identificando otras ciudades, pero al referirse a Perú, es muy probable que quisiera decir Lima, ya que esta es la capital del país.

Con respecto a Lima, Ludena (2002) argumenta que durante el primer periodo de la república, esta ciudad modificó las viejas estructuras que se habían mantenido sin alteración, alguna por más de trescientos años. Todos aquellos rasgos presentes en el siglo XX hasta hoy, serán parte de un camino trazado en esta primera fase. En este sentido, al igual que muchas otras ciudades, hay una clara intención de orientar las clases altas hacia un lugar específico del territorio, y este sería hacia el sur, bordeando la costa, pero también hacia las colinas con el barrio de La Molina.

Leguía y los que le sucedieron reforzaron y continuaron la orientación y la lógica de crecimiento urbano establecida o sugerida por Piérola al reforzar el triángulo Lima-Magdalena-Miraflores, y al fijar, con el Paseo Colón y la urbanización respectiva, la dirección sur como la zona a la que debía dirigirse el emplazamiento del hábitat de la clase alta limeña.

En el caso de Bogota Delaunay y Dureau (2004) han encontrado que desde el año 1940, la clase alta bogotana se desplazó hacia el lado norte y al oriente, cerca de las colinas y es justamente esta clase alta la que “"se preocupa por la calidad el medio ambiente de la localidad" tal como lo menciona Jara en su introducción. Similar situación encuentra Carola y Lacabana (2001) en el contexto de la ciudad de Caracas. Para la ciudad de México, si bien es cierto los barrios pobres se encuentran bastante disper- 
sos en todas las direcciones, la clase alta se las ha arreglado para construir muros que dan cuenta de una segregación no solo simbólica, sino al mismo tiempo física, Parnreiter (2005).

En un trabajo desarrollado para entender la dinámica de la ciudad latinoamericana, Borsdorf, define características generales para el espacio urbano del continente y encuentra que las urbes, en el periodo que él denomina segunda fase de rápida urbanización (1920-1970), era común encontrar que los ricos desplazados del centro hacia barrios más exclusivos con calles amplias y grandes extensiones de áreas verdes. Barrios, que en una última instancia se comienzan a amurallar-

Hacia el final de esta época nacen los primeros centros comerciales, como replicas de los Shopping centers estadounidenses, y rápidamente devinieron en focos de crecimiento de nuevos barrios de lujo. Aparecieron también los primeros clubes de campo implementando la idea de un estilo de vida campestre dentro de la ciudad.

En esta primera parte de la introducción, el artista evidencia su propia experiencia al recorrer Latinoamérica. La literatura al respecto da cuenta del nivel de certeza con el que el creador habla. Las características del barrio alto de Santiago se repiten en el resto de las capitales latinoamericanas. Por esto, es que es muy fácil para él advertir estas particularidades, circunscribiéndolas a un lugar, cuyo sentido y significado está imbricado en una determinada categoría de clase.

En la segunda parte de la introducción, el creador da cuenta de un fenómeno que lo acerca más al mundo postmoderno que al sólido modernismo. En esta última etapa del capitalismo, la reproducción de la sociedad mediante un despliegue de imágenes da cuenta de un mundo nuevo y Víctor Jara devela esta sociedad que esta por venir, donde todo es apariencia y en ella el ser humano posmoderno centra su interés.

En la canción se dice una palabra de Recipol. Recipol en Chile es un líquido que pega cualquier cosa, hasta las ideas las pega y hay una tela también que se llama Prolen y según la televisión dice "Prolen viste para triunfar". Es decir uno se viste con un traje Prolen y triunfa en la vida y si tiene un auto marca Peugeot: Peugeot que es una marca francesa, es un modelo lindísimo, eh y un terno de estos Prolen, solucionó todos los problemas de su vida y logro los objetivos fundamentales. Esta canción se llama las casitas del barrio alto y esta inspirada en Little Boxes de Pete Seeger.”

En esta introducción, Víctor Jara traza líneas de un esbozo de la posmodernidad, sutiles reflejos de lo que estaba por venir. Sin duda para él, en esta nueva época había naufragado la razón moderna, la cual de acuerdo a Quintana de Uña (2004), fue victima de su ambicioso proyecto de absolutidad. Sin poder satisfacer las interrogantes actuales de este universo cada día menos coherente e imprevisible, el ser humano echó al suelo la 
diosa modernidad y su fe ciega en la ciencia. Adorno y Hokheimer, hicieron una profunda crítica a una modernidad que de acuerdo a ellos había fracasado, ya que en su intento por dominar la naturaleza, a través de la razón objetiva, había terminado por someter a los seres humanos a la dominación de las cosas. Estas cosas son las cuales el artista presta especial atención al decir que, los problemas se resuelven si uno las tiene y con esto se "logran los objetivos fundamentales de la vida".

Sin duda la función de los objetos señalados, va por lo que ellos representan en la sociedad contemporánea. En este sentido Baudrillard (1997) nos clarifica que los objetos no pueden intercambiar su función denotativa, es decir lo que en la practica realizan, pero si la función connotativa y esta es intercambiable ya que representan estatus, riqueza, buen diseño, etc.

El cuerpo también presentado en la introducción a través de "prolen viste para triunfar” representa una preocupación para Víctor Jara, el sujeto es definido por la vestimenta y desde esta, el individuo está incluido o excluido, depende sea el caso, de una determinada sociedad. En este sentido, Quintana de Uña (2004) en su libro argumenta que "la austeridad ha dado paso a la gratificación de todos los deseos, a una bulimia consumista sin límites, que tiene el cuerpo por objeto central de nuestra vida. Vivimos para el cuerpo y para la imagen”.

Aun cuando los bienes suntuarios que hoy día den prestigio ya no sean un terno Prolen o un auto Peugeot, sin duda la diversificada oferta de bienes otorgan un prestigio social y en esto se basa la posmodernidad. La diversidad de mercancías en el mercado para alcanzar esa satisfacción, esta dado por la apertura de los mercados a partir de la década de los 1990. De acuerdo Larrain, quien dice que recién en la década de los noventa America Latina comenzó a deshacerse de su identidad barroca y esto a consecuencia del impacto de las mercancías del capitalismo industrial.

En este sentido la globalización, con sus distintas escalas, ha incorporado al país dentro de la estructura mundial de consumo y de apetencias a raíz de una oferta ilimitada de productos. Sin duda en este sentido, Cohen (2007) al reflexionar sobre la globalización establece que esta, si bien no otorga prosperidad al conjunto de países pobres, difunde sus imágenes de opulencia y esta es la diferencia entre esta y otras globalizaciones pasadas, convierte al mundo en espectador. Aún cuando según Baudrillard el consumo de bienes no esta dado por el placer que estos otorgan sino más bien por un deber social, lo cual de acuerdo a él nos conduce a los éxtasis histéricos de la sociedad actual (Baudrillard, 1997)

En la tecno cultura actual los objetos, especialmente los electrónicos, se apropian de los espacios privados, transformando a la casa en mundo y al automóvil en una extensión de esta. En este sentido, Víctor Jara le da una tremenda importancia al televisor como transmisor de imágenes de 
opulencia, a través del cual, entraban en los hogares las símbolos de aquello que daba prestigio. También menciona el automóvil, como un eje futuro de las relaciones de estatus, solo que la oferta hoy es tan variada y se ha expandido a la población que estos objetos que antes daban estatus hoy se convierten en un deber social como lo dice Baudrillard.

Joan Jara (2007) en su libro, Víctor, un Canto Inconcluso, cuenta que “a él le llamó poderosamente la atención la canción Little Boxes de Malvina Reynolds, interpretada por Pete Seeger y Víctor quiso hacer una adaptación chilena a esta. "Las casitas del barrio alto", en las que la suave sátira sobre la vida de las villas en hilera con vista a San Francisco se aplicaba mucho más cáusticamente al barrio alto de Santiago”.

\author{
"Las casitas del barrio alto \\ con rejas y antejardín, \\ una hermosa entrada de autos \\ y esperando un Peugeot. \\ Hay rosadas, verdecitas, \\ blanquitas y celestitas, \\ las casitas del barrio alto \\ todas hechas con recipol. \\ Y las gentes de las casitas \\ se sonríen y se visitan. \\ Van juntitos al supermarket \\ y todos tienen un televisor. \\ Hay dentistas, comerciantes, \\ latifundistas y traficantes, \\ abogados y rentistas \\ y todos visten polycron. \\ (y todos triunfan con prolén) \\ Juegan bridge, toman martini-dry \\ y los niños son rubiecitos \\ y con otros rubiecitos \\ van juntitos al colegio high. \\ Y el hijito de su papi \\ luego va a la universidad \\ comenzando su problemática \\ y la intríngulis social. \\ Fuma pitillos en Austin mini, \\ juega con bombas y con política, \\ asesina a generales, \\ y es un gángster de la sedición.”
}

Las casitas del barrio alto, definidas claramente con rejas y antejardín, se contraponen a la vivienda obrera conocida hasta entonces. Para Víctor Jara, este era un rasgo singular y definitivo al momento de caracterizar las viviendas del barrio alto. Muy acostumbrado a frecuentar los barrios obreros de la capital, donde las rejas y el antejardín daban lugar al cité de los barrios inmediatamente aledaños al perímetro central de la capital. Vivien- 
das de fachada continua, cuyas tipologías apropiadas para la clase obrera, de acuerdo a Hidalgo (2007) "al alinear viviendas en torno a un eje perpendicular a la calle, el cité consigue aprovechar completamente el terreno, creando a la vez un espacio común de acceso que, entre otras funciones, sirve de acceso, patio y jardín”.

La definición de clase por aquella época estaba dada por la referencia al supermarket, el televisor, los automóviles, bienes y servicios reservados solo para una clase social en Chile. Hacia el año 1987 Joaquín Lavín, un personaje emblemático de la derecha chilena de los años 80 y parte de quienes ayudaron a consolidar el modelo neoliberal, usualmente llamados Chicago Boys, escribió un libro llamado Chile la revolución silenciosa. En este libro abordó las profundas transformaciones que estaba viviendo la sociedad chilena.

Si bien es cierto el libro fue considerado una banalidad para los círculos intelectuales, introduce ciertos datos y perspectivas interesantes para entender las profundas transformaciones de la época y el pensamiento detrás de estas. El autor establece que "el numero de automóviles paso de 262.000 en 1976 a mas de 600.000 en 1985”. Lo propio hace con los televisores, donde "según las cifras del ultimo censo, el numero de televisores en los hogares chilenos paso de 335.388 en 1970 a 1.932 .575 en 1982”. Esto último da una clara idea de que efectivamente en cuanto al acceso de bienes suntuarios, el país había cambiado, aun cuando la dirección tomada no reflejó cambios cualitativos en aspectos relevantes para mejorar la calidad de vida de los habitantes.

La sociedad chilena estratificada en clases, desde la época de los conquistadores tenía como particularidad en su clase alta el estar compuesta por descendientes de españoles vascos, a los cuales se habían agregado descendientes de inmigrantes de otros estados europeos. Para Víctor Jara, todos ellos representaban la élite oligárquica, cuyas privativas características eran determinadas por constituirse en comunidades adscritas a determinados colegios, universidades, etc.

Sin duda en la última parte de la canción, el tono de esta se aparta de lo sarcástico y denuncia la abominable acción de ciertos individuos pertenecientes a grupos de extrema derecha, quienes a través del asesinato del general Rene Schneider intentaban establecer una atmosfera de caos en el país.

Víctor añadió un verso que borraba las sonrisas, referido a los pistoleros de derecha que paseaban con sus minis y que convertían en un deporte el asesinato de generales. Ese verso producía un siniestro contraste con la vivaz polca de la melodía. Posteriormente Malvina hablaría favorablemente sobre la "elevación política” de su canción. Víctor hostigaba a la derecha utilizando como arma el humor, (Jara, 2007) 


\section{Consideraciones finales}

Dentro de este trabajo, se evidencia que las características enunciadas por Víctor Jara en su canción "las Casitas del Barrio Alto” en la ciudad de Santiago y otras grandes urbes de Latinoamérica, con el correr del tiempo se encuentran presente, no sólo en las otras metrópolis del país, (Concepción y Valparaíso) además de Santiago, sino que en la actualidad se observan en todas las ciudades intermedias del país.

La intuición matematizadora de Víctor Jara, revela una precisión bastante ajustada del fenómeno urbano derivado del modelo impuesto a partir de la dictadura militar en Chile. Sin embargo este modelo, sólo comenzó a operar hacia finales de la década de 1970, con las reformas llevadas a cabo por los economistas chilenos graduados en la escuela de Chicago en Estados Unidos.

Víctor Jara, es en sí mismo una transición entre el modernismo y el posmodernismo. Capaz de develar fenómenos imperceptibles para sus contemporáneos, evidenció el rol que vendrían a cumplir los objetos en la definición del sujeto actual.

Fiel militante del pensamiento político de una época, se la jugó porque su creación contribuyera a despertar la conciencia del país en torno a los temas urgentes de su tiempo. No obstante esta misma característica sería la que lo llevaría a sucumbir a manos de quienes tenían el proyecto de una transformación radical de la nación. En esto último, quienes tuvieron el encargo, no trepidaron en eliminar las fuentes amenazantes para sus propósitos, Víctor Jara, quien con la lucidez de su intuición matematizadora, sin duda lo habría sido. 


\section{Notas}

${ }^{1}$ Trabajo desarrollado en el marco del Doctorado de Ciencias Humanas, Discurso y Cultura. Universidad Austral de Chile.

${ }^{2}$ Este concepto ha sido creado por el arquitecto Gonzalo Martínez de Urquidi, cuyas charlas al respecto me han permitido establecer que, este tipo de intuición encierra el acto de la observación de fenómenos embrionarios, cuya proyección en el mediano o largo plazo los convierte en tendencias urbanas.

${ }^{3}$ Se construyó la Avenida Circunvalación Américo Vespucio alrededor de la ciudad. Además, fue habilitada la Carretera Panamericana o Avenida Norte-Sur, cuyo eje cruzaba transversalmente la ciudad, y por último se ensanchó las principales avenidas de la ciudad, como la Alameda que para ese entonces ya era la principal ruta de circulación de los automóviles en la capital. 


\section{Bibliografía}

Baudrillard, J. (1997), "The end of the millenium or the countdown". Economy and society vol. 26 (4): 447-455.

Cariola, C. y Lacabana, M. (2001), “La metrópoli fragmentada: Caracas entre la pobreza y la globalización”. Eure vol. 27 (80): 9-32.

Cohen, D. (2007), Tres lecciones acerca de la sociedad postindustrial, Katz Editores, Madrid.

Delaunay, D. y Dureau F. (2004), “Componentes sociales y espaciales de la movilidad residencial de bogota”. Estudios demográficos y urbanos. 55 (enero y abril): 77-113

De mattos, C. (1999), “Santiago de Chile, globalización y expansión metropolitana: lo que existía sigue existiendo”. Eure vol.25 (76): 29-56.

Ducci, M. (1998), “Santiago, ¿una mancha de aceite sin fin? ¿qué pasa con la población cuando la ciudad crece indiscriminadamente?”. Eure vol.24 (72): 85-94.

Harvey, D. (1990), The condition of postmodernity, Blackwell, USA.

Hidalgo, R. (2007), 1906/2006 Cien años de política de vivienda en Chile, Serie Geolibros-UC, Santiago.

Jara, J. (2007), Víctor, un canto inconcluso, Lom Ediciones, Santiago.

Lavin, J. (1987), Chile revolución silenciosa, Editora Zig-Zag, Santiago.

Ludena, W. (2002), “Lima: poder, centro y centralidad: del centro nativo al centro neoliberal”. Eure vol.28 (83):45-65.

Massey, D. y Jess, P. (1995), A place in the world?: places, cultures and globalization, Oxford university press inc., New York

Mathew, F. (2003), "Disaster and decentralization: american cities and the cold war”. Cultural geographies, vol.10: 125-148.

Parnreiter, C. (2005), “Tendencias de desarrollo en las metrópolis latinoamericanas en la era de la globalización: los casos de Ciudad de México y Santiago de Chile”. Eure vol.31 (92): 05-28.

Quintana de Uña, D. (2004), El síndrome de epimeteo occidente la cultura del olvido, Editorial Cuarto Propio, Santiago.

Sabatini, F. y Arenas, F. (2000), “Entre el Estado y el mercado: resonancias 
geográficas y sustentabilidad social en Santiago de Chile”, Eure vol.26 (79): 95-113.

Tomic, P. y Trumper R. (2006), “Transporte y poder: el Metro de Santiago de Chile”, pp. 163-175 in Horacio Capel, Horacio and Rodrigo Hidalgo (ed). Construyendo la ciudad del siglo xxi. Retos y perspectivas urbanas en España y Chile, serie Geolibros, Universidad Católica de Chile, Santiago.

Valdivia, V. (2001), "Estatismo y neoliberalismo: un contrapunto militar. Chile 1973-1979”. Historia vol.34:167-226.

Vilches, P. (2004), “De Violeta Parra a Víctor Jara y Los Prisioneros: recuperación de la memoria colectiva e identidad cultural a través de la música comprometida”. Latin American Music Review vol. 25 (2) fall/winter: 195215. 